\title{
Cooperação, Colaboração e Mercado na Cibercultura
}

\author{
Henrique Antoun ${ }^{1}$ \\ Universidade Federal do Rio de Janeiro
}

\begin{abstract}
Resumo: Este trabalho visa estimar o futuro da democracia na cibercultura, considerando as transformações introduzidas pelas redes interativas de comunicação distribuída para o governo da sociedade. As comunidades virtuais e as redes de parceria têm gerado os principais problemas de governabilidade para o Estado pós-moderno. A hipótese básica de orientação é a de que as redes interativas de comunicação distribuída sediadas na Internet geram uma oposição entre a informação e a comunicação, exprimindo o conflito entre o trabalho imaterial comunicacional $e$ a propriedade privada da informação. Esse conflito vai ser gerenciado através das interfaces de comunicação pela relação entre os diferentes modelos de construção de seus códigos $e$ as diferentes práticas de valoração $e$ qualificação social que permitem com seus dispositivos. Isto gera uma grande diferença no modo como o público consome e experimenta a si mesmo na sociedade atual. Enquanto no mercado de massa ele é o homem médio da curva de Bells assediado pelos produtos arrasa quarteirão (blockbuster); na Internet ele é o ativista da lei de potência explorando a cauda longa (long tail) do mercado de nicho.
\end{abstract}

Palavras-chave: Cibercultura, Cauda Longa, Lei de Potência, Comunidades Virtuais, Redes de Parceria.

\footnotetext{
1 Henrique Antoun é Doutor em Comunicação (1993) pela Escola de Comunicação da Universidade Federal do Rio de Janeiro. Pesquisador do quadro principal do Programa de Pós-Graduação de Comunicação da supracitada instituição, desde 2001 desenvolve pesquisa no CIBERIDEA - Núcleo de Pesquisa em Tecnologia, Cultura e Subjetividade - sobre as transformações da mediação social e da organização do público ocasionada pela entrada em cena da Internet e suas redes interativas de comunicação distribuída.
} 


\begin{abstract}
The paper tries to evaluate the future of the democracy in the cyberculture, taking on account the introduced transformations from interactive distributed communication's networks to the society's government. The virtual communities and peer-to-peer are the post-modern State's main agents of governability troubles. The leading ground hypothesis is that interactive distributed communication's networks settled in the Internet create an opposition between information and communication expressing the conflict between immaterial communicational labor and the private information's property. This conflict will be managed by the communication's interface through the relationship between the different building code models and the different social evaluation and qualification practices that is allowed by its devices. It did a great difference in the way as the public consume and experiences itself in the actual society. Meanwhile in the mass market he is the Bells 'curve middle man harassed by the blockbuster products; in the Internet he is the power law's activist exploring the niche markets`long tail.
\end{abstract}

Key Words: Cyberculture, Long Tail, Power Law, Virtual Comunities, Peerto-Peer.

Resumen: Este trabajo tiene como objetivo evaluar el futuro de la democracia en la cibercultura, en vista de las transformaciones introducidas por las redes interactivas de comunicación distribuida para el gobierno de la sociedad. Las comunidades virtuales y las redes par-a-par han generado los problemas principales de la gobernabilidad para el Estado pos moderno. La hipótesis básico de orientación es que las redes interactivas de comunicación distribuida ubicadas en la Internet generan una oposición entre la información y la comunicación, expresando el conflicto entre el trabajo incorpóreo comunicacional y la propiedad privativa de la información. Ese conflicto va a ser manejado en las interfaces de la comunicación por intermedio de la relación entre los diferentes modelos de la construcción de sus diversos códigos y las diferentes prácticas de valuación y calificación social que permitan con sus dispositivos. Esto genera una gran diferencia de la manera como el público consume y experiencia a si propio en la sociedad actual. Mientras que en el mercado masivo es el hombre medio de la curva de Bells asediado por los productos del arrasa bloque (blockbuster); en el Internet es el activista de la ley de la potencia que explora la cola larga (long tail) del mercado de nicho.

Palabras Clave: Cibercultura, Cola Longa, Ley de la Potencia, Comunidad Virtual, Par-a-Par. 


\section{Introdução}

Este trabalho analisa as perturbações trazidas para a prática democrática através da comunicação em rede e as transformações na mediação que ela acarreta. Partindo das perspectivas tanto do crescimento do ativismo dos grupos na sociedade; quanto do dominante uso instrumental da informação filtrada, como características atuais da cibercultura, (Cole e Suman (orgs.), 2000) vamos examinar o estranho paradoxo que parece opor o poder da informação ao poder da comunicação nas praticas sociais. (DyerWitheford, 1999, p. 85-86) Enquanto, por um lado, o poder da informação constituiria o campo das minas de dados, da propriedade intelectual, da venda de serviços e espetáculos através da rede tecnológica; o poder da comunicação, por outro lado, investiria e ampliaria o campo da partilha de conhecimentos e bens, da criação de valores, da resolução dos dilemas da ação coletiva e da geração de mercados e bens comuns. Deste modo a informação exprimiria o poder da propriedade e da exploração do capital social como um poder de extorquir cooperação; enquanto a comunicação exprimiria o poder de valoração e organização autônomas do trabalho como uma potência da parceria.

Esta perspectiva sobressai se for posto em relevo a atuação dos grupos de interesse, e os problemas emergentes da governabilidade democrática do Estado, dentro do processo de globalização. Através das redes de luta, produção e resistência — que hoje incorporam intensamente as tecnologias informacionais de comunicação (TIC) nos processos de comunicação mediada por computador $(\mathrm{CMC})$ - os grupos de interesse (corporações, ONGs, movimentos, etc) teriam se emancipado da tutela das instituições do Estado, tornando-se ingovernáveis pelas formas tradicionais da representatividade democrática mediada pelas instituições. Para compreender este problema é preciso tomar em consideração algumas questões envolvendo o problema da cooperação e do conflito na sociedade em vista da gestão e da promoção do bem comum (Hardin, 1968 e Frauenfelder, 2002). Se ele tradicionalmente pertencia à esfera da economia política, vai resvalar na atualidade para outras áreas de conhecimento envolvendo a modelização matemática das redes, as leis da formação de rede e a teoria dos jogos, a partir dos dilemas da ação coletiva (Kollock, 1998). 
Embora as tradicionais relações entre trabalho e tecnologia, um dos motes fundamentais da economia política, a princípio não pareçam fazer parte desta nova forma de interpretar o problema é possível mostrar como sua dinâmica constitui o motor do desenvolvimento da propalada "revolução tecnológica", desde que se aceite rever o quadro tradicional da interpretação destas relações (Marx, 1988). ${ }^{2}$ Agindo assim torna-se visível que o trabalho, longe de estar confinado apenas ao papel do posto perdido e da vida desamparada, se constitui como o principal fator de desenvolvimento da sociedade em rede (Negri, 1989). Necessário assinalar que este trabalho não se confunde apenas com o tradicional poder de trabalho assalariado pelo capital, mas envolve, sobretudo, o trabalho imaterial, voluntário e ativista engajado em um vasto número de projetos vinculados a empresas sem fins lucrativos, grupos de atividades ou movimentos emancipatórios de advocacia (Lazzarato e Negri, 2001). Este novo tipo de trabalho, capaz de mobilizar milhões em todo o mundo, se funda em um jogo de parcerias anônimas e produtivas. Ele esta baseado nos serviços de comunicação fornec idos através dos correios eletrônicos (email), grupos de discussão (newsgroups), salas de conversa (chat), teias de documentos (webpages), teias de comunicação (blogs), mensagens curtas (sms), faxes, celulares e outros mais que fazem parte do universo constituído através das TIC e CMC (Vaidhyanathan, 2004).

O quadro de historicidade a partir da qual são estabelecidas as atuais descontinuidades é a passagem da Modernidade à Pós-Modernidade, considerando o surgimento das novas tecnologias de informação e comunicação tanto no aspecto do desenvolvimento dos conhecimentos vinculados aos problemas do controle - cibernética, informática, genética (Deleuze, 1992) -, quanto no aspecto das lutas anti-disciplinares dos anos 60 e 70, que realizam a ruptura entre a plena vigência dos dispositivos de disciplina e a predominância dos dispositivos de controle como mecanismos dominantes nas relações de

\footnotetext{
${ }^{2} \mathrm{Na}$ interpretação tradicional do marxismo as tecnologias são meios de produção apropriados pela burguesia através da propriedade privada. Elas constituem um trabalho "morto" (um trabalho passado) utilizado pela burguesia para explorar o valor do trabalho "vivo" (trabalho presente) da força de trabalho. Neste sentido elas exprimem o interesse burguês e manifestam seu poder de exploração. Deste modo a evolução científica e tecnológica seriam sempre interpretadas como um vetor do interesse burguês de maximizar o ganho exploratório que aumenta o poder do capital em sua relação com o poder do trabalho, constituindo a dialética da força de trabalho e a contradição entre os meios de produção e o trabalho vivo nas relações de produção.
} 
poder (Negri e Hardt, 2001). Tendo como premissa básica que os dispositivos disciplinares têm por preocupação a moldagem do corpo em função da ordem, centrando-se nos problemas de comando e obediência, enquanto os dispositivos de controle privilegiam a modulação da variação do movimento no tempo, desenvolvendo-se nas questões que visam realizar a regulação entre a simultaneidade de ações e a formação de fluxos (Deleuze, 1992); vamos examinar com especial interesse as relações entre as forças do trabalho e as forças do capital em seu esforço simultâneo por integração - composição com as demais forças - e autonomia - busca de hegemonia sobre as demais forças - (Dyer-Witheford, 1999).

Para um primeiro exame deste paradoxo vamos considerar dois blocos de problemas, relevando as questões da relação entre a mediação e a mobilidade nas formações de base da cibercultura para a sociedade; a saber, as comunidades virtuais e as redes de parceria. Em primeiro lugar o problema do valor da cooperação e do conflito para a governabilidade democrática a partir da emancipação das organizações em rede que não geram teias de cooperação sem, ao mesmo tempo, constituir redes de confronto. Esta questão releva a integração e a dissolução da ordem social a partir da entrada em cena da virtualidade na formação das comunidades e dos objetos, com sua oscilação entre a cristalização e o movimento. Em segundo, o problema do sentido da colaboração e da disputa para a ordenação social, a partir da emergência das redes de parceria. A disseminação das redes virtuais no âmbito da produção e da troca transforma o sujeito e a ação na sociedade, pois nelas a competição é indissociável da colaboração e a disputa se alia à partilha. As formações em rede oscilam sem cessar entre a hierarquia e a anarquia.

A estas considerações iniciais vamos acrescentar, por um lado, uma avaliação das transformações qualitativas introduzidas pela virtualidade nas noções de coisa e de lugar de forma a afetar o modo de conceber a comunidade e a propriedade. Por outro lado, vamos avaliar a mudança qualitativa trazida pela mobilidade para a noção de agente e ação de forma a afetar o modo de conceber o sujeito e a causalidade. Dessas análises vai sobressair a transformação do público com a emergência do mercado de nicho provocada pela emergência da cauda longa produzida pelo comércio eletrônico. 


\section{Informação, Guerra e Cooperação}

Para compreender os modos emergentes de cooperação e conflito, surgidos na sociedade contemporânea a partir da revolução tecnológica que construiu a infra-estrutura do ciberespaço, os pesquisadores da RAND ${ }^{3}$ Arquilla e Ronfeldt criaram em 1993 mesmo ano da popularização da noção de comunidade virtual (virtual community) — a noção de guerra em rede (netwar) ${ }^{4}$ (Arquilla e Ronfeldt, 1993). Ela seria o oposto correlato da noção de guerra de controle (cyberwar), também por eles gerado na mesma ocasião, ambos constituindo a maior parte do campo da guerra da informação (infowar) no mundo atual (Arquilla e Ronfeldt, 1993).

A guerra da informação tem como um de seus fundamentos a disciplina do gerenciamento da percepção, sendo essencialmente o uso da informação para confundir, decepcionar, desorientar, desestabilizar e desbaratar uma população ou um exército adversário (Schwartau, 1995). O importante nesta guerra é a inserção de falsidades na percepção do adversário, prevenindo-se de que ele possa fazer o mesmo, e a adivinhação de seus segredos, garantindo um domínio na condução da ação pelo poder de decepção adquirido. Em termos gerais toda operação conduzida para explorar informações para obter uma vantagem sobre um oponente e para negar ao oponente informações que poderiam lhe trazer uma vantagem faz parte da guerra de informações (Kopp, 2000). Enquanto a guerra do controle compreenderia a luta de alta intensidade conduzida através de alta tecnologia militar travada por dois Estados, a guerra em rede seria a luta de baixa intensidade travada de modo assimétrico por um Estado e grupos organizados em rede,

\footnotetext{
${ }^{3}$ A RAND Corporation é uma das principais agências independentes de fomento à pesquisa sobre temas de interesse do Departamento de Defesa dos Estados Unidos da América. A marca "RAND" foi formada pela contração das palavras "research and development" (pesquisa e desenvolvimento) e a Agência foi criada em 1946 pela Aeronáutica dos Estados Unidos como uma empresa independente e sem fins lucrativos com a finalidade de promover através da pesquisa e da análise o desenvolvimento de material que auxiliasse a elaboração de políticas e a tomada de decisões no âmbito da defesa e da segurança nacional e internacional dos Estados Unidos.

${ }^{4} \mathrm{O}$ termo netwar tanto pode ser traduzido por guerra em rede, como por rede de guerra. Na medida em que a guerra em rede remete a tipos específicos de organização em rede, como o Al Qaeda, o Greenpeace ou o DAN (Direct Action Network), preferimos usar o termo rede de guerra para designar esta forma de organização, usando guerra em rede para designar o tipo de conflito. Importante assinalar que as características apontadas pelos pesquisadores da RAND como pertencentes à guerra em rede e suas redes de guerra são as mesmas apontadas por Deleuze-Guattari para caracterizar as maquinas de guerra (Deleuze e Guattari, 1980, p. 434-527).
} 
usando de táticas e estratégias que envolvem o intenso uso das TIC, da CMC e da Internet (Arquilla e Ronfeldt, 1996, p. VII).

A guerra em rede tem uma dupla face composta, por um lado, de conflitos travados por extremistas, sejam eles terroristas, criminosos ou etnonacionalistas; ${ }^{5}$ e, por outro lado, de lutas conduzidas por ativistas da sociedade civil. O que distingue a guerra em rede como uma forma de conflito é a estrutura organizacional em forma de rede de seus adeptos - com vários grupos estando atualmente estruturados no modo da resistência sem líder (leaderless) (BEAM, 1992) - e a sua ultra flexível habilidade de atingir rapidamente qualquer lugar em ataques de afluência (swarming attacks) ${ }^{6}$ (Arquilla e Ronfeldt, 2000) aglutinadores de multidão (Arquilla e Ronfeldt (orgs.), 2001, p. 311-361). O poder, ao mesmo tempo, maleável e integrador das redes interativas de comunicação distribuída favoreceria a informalidade das redes sociais, contra a rígida forma hierarquizada das instituições do estado, centradas e localizáveis, no conflito entre grupos assimétricos (Arquilla e Ronfeldt, 2001).

Ferrenhos adeptos da determinação tecnológica - na qual enxergam uma destinação transcendental que privilegiaria a promoção do espírito (Arquilla e Ronfeldt, 1999) —, eles acreditam que o design organizacional da rede condiciona a extensão da integração dos participantes e a disposição do grupo. Deste modo a capacidade de ação dos agentes da rede, que compõe sua dimensão doutrinária, depende em larga medida da adequação entre o design e a doutrina. (Arquilla e Ronfeldt, 2001) A rede segmentada policêntrica ideologicamente integrada (segmented, polycentric, ideologically integrated network - SPIN) - dominante na estrutura dos movimentos sociais americanos dos anos 60 e 70 (Gerlach, 1987) — serviria de paradigma para a organização dos grupos contemporâneos envolvidos com a guerra em rede: ela é segmentada porque se compõe de diferentes grupos em modo celular; ela é policêntrica porque possui muitos centros de direção ou líderes; ela é integrada porque os líderes e os segmentos estão dispostos em um

\footnotetext{
${ }^{5}$ Sobre a relação da emergência destes atores com a destruição da unidade forjada pela criação do Estado-Nação, acreditamos ser de suma importância a leitura de um antigo trabalho de Foucault capaz de empalidecer essa falácia (Foucault, 2002).

${ }^{6}$ A importância da afluência (swarming) como forma de ação coletiva em rede descentralizada já havia sido apontada antes por Kevin Kelly (1994).
} 
reticulado de sistemas ou redes através de vários vínculos estruturais, pessoais e ideológicos. Como sua sigla SPIN sugere, ela se movimenta rodopiando como uma espiral de modo fluido, dinâmico e expansivo sobre a sociedade. (Arquilla e Ronfeldt, $2001 \mathrm{e}$ Gerlach, 1987) Do ponto de vista da segurança do Estado a situação parece alarmante e incontrolável, pois a forma SPIN permite que as organizações criminosas possam trabalhar em rede, cooperando umas com as outras independente de sua rivalidade - fundindo especialidades, alargando o leque de atividades, compartilhando informações, serviços, recursos e acessos ao mercado. Mesmo assim, haveria uma oportunidade promissora se o Estado cooptasse os atores da sociedade civil através das questões legítimas de importância mútua, como democracia e segurança, aprendendo a se comunicar, coordenar e agir conjuntamente com eles (Arquilla e Ronfeldt, 2001).

As redes de movimentos emancipatórios da sociedade civil traçam, entretanto, um diagnóstico diferente da realidade social através de suas práticas. Por um lado acreditam que as organizações em rede vinculadas à ordem econômica e política mundial, como, por exemplo, o FMI, o Banco Mundial, a OMC e o clube de Davos são estruturados para explorar, de forma predatória, o poder de cooperação das redes que se exprime como capital social através do trabalho imaterial simbólico e afetivo (Negri e Hardt, 2001). A integração da sociedade realizada pelas TIC, porém, estaria permitindo que a resistência à exploração ultrapassasse os limites da oposição e da reivindicação, possibilitando que amplas redes de colaboração e produção pudessem emergir integrando diferentes movimentos de diferentes grupos em comunidades de movimento e produção (Cleaver, 1994).

O movimento Zapatista emerge como um exemplo do ultrapassamento da segmentaridade das organizações em rede, exprimida através da integração ideológica de suas doutrinas (etnonacionalismos, fundamentalismos, proteção do meio ambiente, proteção das mulheres, proteção dos indígenas e etc.), na direção de um movimento de ampla colaboração - reunindo o Exército Zapatista de Libertação Nacional (EZLN), as comunidades indígenas de Chiapas e diversas Organizações Não-Governamentais (ONGs) mexicanas e internacionais — fundado na criação de uma agenda de ação comum 
construída em quatro congressos com ampla participação dos parceiros nas selvas de Chiapas em 1994 (Cleaver, 1994 e Arquilla, Ronfeldt, Fuller e Fuller, 1998).?

O processo de construção da aliança além de criar uma nova organização, conectou várias espécies de lutas, que estavam anteriormente desconectadas e separadas. $\mathrm{O}$ Movimento Zapatista gerou, ainda, uma rede de trabalho voluntário ativista, coordenada através da Internet de forma descentralizada, composta por digitadores, tradutores, webdesigners, escritores, organizadores de listas de discussão e administradores de sítio (Cleaver, 1994). Esta rede de trabalho voluntário e flutuante forma hoje uma das maiores e mais eficientes empresas de relações públicas do mundo (Wray, 1998), conseguindo traduzir e difundir os comunicados do sub-comandante Marcos para inúmeras línguas diferentes em 24 horas, proeza que mesmo a poderosa empresa Microsoft não consegue igualar com seu trabalho profissional assalariado e seu imenso capital.

Mesmo sem querer marcar uma diferença estrutural que caracterizasse um design diferente do SPIN, Arquilla e Ronfeldt já diferenciavam o desenho da rede de guerra do Movimento Zapatista e da Batalha de Seattle dos demais desenhos. Elas teriam um dos padrões ordenados descobertos por teóricos da complexidade na área das ciências exatas e sociais interessados em discernir os princípios comuns que explicam a arquitetura da complexidade através dos sistemas naturais e humanos; padrões presentes na estrutura e na dinâmica dos sistemas biológicos, ecológicos e sociais onde a rede é o princípio de organização. (Capra, 1996) Este padrão se assemelha a uma rede de teia de aranha com multi-eixos bem estruturados; ou um grupo de redes centro/periferia interconectados. Sua topologia se caracteriza por um pequeno número de nós fortemente interconectados que agem como eixos (bubs), aos quais se conectam um grande número de nós de fraca conexão, mesmo que partilhando uma ligação "todos os canais". Socialmente este tipo de padrão se caracteriza por um ou mais atores operando como eixos chaves, em torno dos quais estão ordenados um grande número de atores ligados aos eixos, embora menos ligados uns com os outros, mesmo que as informações estejam disponíveis e partilhadas no

\footnotetext{
${ }^{7}$ Apesar da divergência ideológica e interpretativa, Cleaver converge com Arquilla e Ronfeldt nessa avaliação.
} 
modo "todos os canais" para todos os atores. Este padrão é muito resistente aos choques sistêmicos (Arquilla e Ronfeldt, 2001).

No exame destes dois tipos de redes de guerra, o nível narrativo reaparece não mais como acessório do design e da doutrina, mas tendo de fato uma faceta constituinte. Por um lado, porque influencia diretamente a resolução do problema da liderança tanto no que diz respeito à organização, quanto o que diz respeito à doutrina, fazendo com que o problema da segmentação da rede possa ser superado. Por outro lado, a narratividade revela uma diferença de natureza e funcionamento na rede que não deriva da forma Estrutural (Arquilla e Ronfeldt, 2001). Embora na conceituação da relação entre narrativa e liderança Arquilla e Ronfeldt já apontem o aspecto mais relevante — o lugar central que a narrativa ocupa na organização e doutrina da rede — parecem ainda estar presos ao velho problema da autoria na narrativa. Mas nestas redes a narrativa é feita por uma multiplicidade grupal, sendo indissociável das conversações recorrentes que geram a montagem e o desenvolvimento da rede, e dos testemunhos que acompanham o desenrolar de seus acontecimentos. A narrativa nestas redes mais se assemelha ao roteiro de um filme experimental, que vai sendo escrito por toda equipe conforme a filmagem se desenrola. De fato as formas de narrativa experimental cinematográficas estão muito mais próximas da realidade narrativa desenvolvida nas redes de teia de aranha.

Isto porque, como nos ensina Barabási, as redes em espiral e teia de aranha são redes de potência livremente escaláveis, onde o crescimento tem uma importância chave na formatação de suas topologias. Elas não são centralizadas como uma rede estrelada, nenhum eixo central encontra-se assentado no centro da teia de aranha para controlar e monitorar cada ligação (link) e nó, (node). Elas se mantêm reunidas por uma móvel hierarquia de eixos (bubs) fortemente ligados (linkeds) entre si que são conectados a vários nós (nodes) menos fortemente ligados (linkeds), desdobrando-se em dúzias de outros nós (nodes) ainda menores, de modo que não há um único nó (node) cuja remoção possa quebrar a teia. Este tipo de rede forma uma teia sem aranha, auto-organizada, oferecendo o vívido exemplo de como as ações independentes de milhares de nós (nodes) e ligações (linkes) podem conduzir a um espetacular comportamento de emergência (Barabási, 2002, Johnson, 2001). 


\section{Comunicação, Parceria e Colaboração}

As questões que giram em torno da ação coletiva e do bem público são uma constante na teoria da comunicação, bem como na sociologia, economia política, filosofia política e teoria dos jogos. Elas envolvem os meios de comunicação na medida em que eles transformam os modos como as pessoas colaboram, sobretudo se eles transformam as maneiras como elas vêem a si mesmas e como os outros as vêem. A reputação é um forte indutor de cooperação ou defecção (Goffman, 1959). Meios de comunicação também podem reduzir os custos de resolução dos dilemas da ação coletiva, possibilitando que mais pessoas possam gerar e compartilhar recursos de novos modos. Os dilemas da ação coletiva estão na base dos problemas que giram em torno da partilha do bem comum (commons) na medida em que se procure entender essa oscilação de cada um entre seu próprio interesse e o bem público (Smith, 2000).

A teoria da necessidade do estado coercitivo, nascida com Hobbes, considera que o egoísmo competitivo faz com que o estado natural seja a guerra de todos contra todos, o que dilapidaria o bem comum e imporia a todos miséria e sofrimento, a menos que um soberano impusesse o terror a todos, forçando a colaboração. Se a soberania despótica não é capaz de promover o bem comum ela ao menos consegue impedir sua dilapidação pela administração de seu uso (Hobbes, 1997).

Locke vai discordar de Hobbes, considerando que os homens podiam se governar melhor através de contratos sociais, e que o gerenciamento privado do bem comum, através da propriedade privada, não apenas impedia sua dilapidação mas promovia sua multiplicação pela expectativa de ganho gerada, tornando o interesse de cada um por si mesmo num poderoso vetor de cooperação e alargamento do bem público (Locke,1952).

De qualquer forma, a soberania do estado permanece intocada nesta teoria, para o despotismo ou para a democracia, com o egoísmo e o interesse próprio sendo considerados os motores da ação individual. A pressão social, do insulto ao encarceramento, para garantir o pagamento das dívidas e o cumprimento das obrigações que supostamente ajudariam as comunidades a manter o bem coletivo da confiança, se tornam necessárias dentro desta perspectiva. (Smith, 2000) A reputação e a pressão dos 
parceiros sociais são as chaves da manutenção dos recursos partilhados em comum. Em ambas as teorias, a colaboração é uma servidão imposta pela soberania e as mediações das instituições do Estado o veículo adequado para administrar as ações e as sanções. A teoria da evolução, baseada na idéia de seleção natural desenvolvida por Darwin, sacramentou a idéia de que o egoísmo era o pai de todos os afetos e a competição era a única força diretriz da evolução (Huxley, 2003). ${ }^{8}$

Kropotkin vai se contrapor a esta interpretação da teoria de Darwin chamando atenção para a cooperação que podia ser extensamente observada no mundo natural: animais se reúnem para se proteger de seus predadores, para caçar em conjunto e para trabalhar juntos de diversos modos. Ele vai defender que os homens estão dispostos ao auxílio mútuo sem coerção autoritária e que não era necessário o governo centralizado para determinar os modelos de bom comportamento e obrigar às pessoas a agir de forma correta, pois elas já agiriam assim muito antes da ascensão do Estado. Ele vai sustentar que é o governo quem reprime nossa tendência natural para a cooperação, acreditando no poder de formação das redes de parceria (Kropotkin, 1989).

Desenvolvida após a II guerra mundial impulsionada pelos problemas da guerra fria, a teoria dos jogos vai experimentar largamente o jogo do dilema do prisioneiro inventado na RAND em 1950. Ele foi gerado para ser um modelo das diversas situações possíveis das possibilidades de cooperação ou defecção entre parceiros. O ponto de partida do jogo é o de que o jogador age apenas no interesse próprio.

No final dos anos 70 o cientista social Robert Axelrod introduziu a iteração na experimentação do jogo. Interessado em descobrir quando alguém se dispõe a cooperar e quando prefere o interesse próprio numa interação com outra pessoa, ele fez o dilema repetir-se entre os dois jogadores. Embora os parceiros não pudessem comunicar suas intenções eles registravam os resultados das jogadas anteriores. O histórico das decisões prévias passou a funcionar como forma de antecipar a intenção do outro jogador. Cada jogador ganhava dessa maneira uma reputação, apesar de seu anonimato. A reputação

\footnotetext{
${ }^{8} \mathrm{~A}$ interpretação dada por Thomas Huxley da teoria da evolução e da seleção das espécies no final do século XIX vai se popularizar nos meios intelectuais e se tornar canônica para o casamento do liberalismo com o darwinismo.
} 
emergia como a sombra do futuro projetada sobre uma interação. Após experimentar vários modelos de programas competindo entre si em computadores oponentes o programa mais bem sucedido — tit for tat — revelou-se o mais simples: o jogador começa cooperativo e responde no lance seguinte com a resposta do oponente no lance anterior. $\mathrm{O}$ jogo do prisioneiro podia transformar-se no jogo da colaboração (Axelrod, 1985).

A parceria esteve na base tanto do funcionamento técnico da Internet como rede, quanto no funcionamento dos serviços de comunicação nela construídos. Sua atual configuração, onde prevalece a relação entre máquinas servidoras e máquinas clientes na base tecnológica ou a formação dos grandes eixos nos provedores, portais e locais de busca na base de utilização, foi introduzido pela ocupação comercial da rede e implicou num largo dispêndio de sua largura de banda, o bem finito do tempo de processamento e atenção que é necessário para a interação. (Minar e Hedlund, 2001) Isto teria ocorrido porque as corporações, privilegiando a chance da oportunidade de comércio aliada à exploração da propriedade intelectual, fixaram-se nos efeitos de valor da rede contidos na lei de Metcalfe. Esta lei reza que o valor da rede cresce no quadrado da quantidade de nós a ela conectados. (Kirsner, 1998) Traduzindo economicamente seu significado, conectar duas redes cria mais valor que a soma de seus valores como redes independentes. (Reed, 1999a) Essa lei privilegia a dissimetria entre os nós concorrentes na estrutura cliente/servidor como forte propiciadora da realização dos negócios, (Barabási, 2002) gerando ao mesmo tempo uma oligarquia da informação (Vaidhyanathan, 2004) e uma marginalização do usuário comum através da massiva concentração de clientes em alguns poucos servidores que monopolizariam o processamento da informação e as ligações hipertextuais (Minar e Hedlund, 2001).

Mas a multidão de usuários formada na Internet reinventou o poder da parceria, seja gerando as teias de comunicação (blogs) capazes de quebrar a invisibilidade do usuário comum nos motores de pesquisa ao criar um circuito cooperativo entre eles; seja inventando os programas que restabelecem a horizontalidade dos parceiros repartindo recursos de banda e processamento para partilhar informações, para ficarmos em dois exemplos (Minar e Hedlund, 2001). Ela tem a seu lado a lei de Reed que afirma que o valor social de uma rede cresce na razão da parceria exponenciada pela quantidade de nós, ou 
seja, dois elevado ao número de nós e não o número de nós elevado ao quadrado. A lei de Metcalfe, inventor da placa de rede Ethernet, mede o valor das interações da rede de computadores, mas a lei de Reed mede o valor da formação de grupos da rede social. A rede ou o serviço de comunicação é bem sucedido na medida em que ele possibilita a formação de grupos sociais em torno de seus interesses ou desejos, gerando valores compartilhados (Reed, 1999).

Se considerarmos que uma rede se transforma conforme muda sua escala, numa rede dominada pela conectividade linear o conteúdo veiculado por suas poucas fontes dominará; numa rede ordenada em eixos (hubs) as transações tornam-se centrais e o que é vendido dominante; e numa rede ordenada pelas parcerias as formações de grupos tornamse centrais e os valores construídos na produção do conhecimento comum dominarão (Reed, 1999). Quanto mais fácil é para as pessoas formar novas associações mais cresce o capital social destas associações, gerando uma maior prosperidade para todos (Rheingold, 2002). As redes de parceria contrapõem ao poder de estoque e propriedade da informação sua potência de comunicação e de gestão auto-organizada do bem comum.

\section{Lugar virtual e propriedade intelectual: Incerteza}

No exame até então realizado sobressaem, por um lado, as questões vinculadas à passagem da propriedade material para a propriedade intelectual, sobretudo pelos limites da aplicação do mecanismo de "não ultrapassamento" na esfera do espaço virtual das redes. Este mecanismo era um dos principais reguladores na relação entre propriedade material e liberdade de expressão. A dificuldade de sua transposição ao universo do espaço virtual e do objeto intelectual responde pelos principais embaraços e disputas na definição da propriedade intelectual (Lessig, 2001). Na propriedade material a limitação da reprodução da matéria garantia o apego ao objeto, a delimitação de sua figura garantia sua individualidade, a imobilidade inercial garantia a fixação de sua identidade e os contornos definidos garantiam os limites da sua propriedade, regulando seu ultrapassamento. A mobilidade do material informacional (dígitos) e comunicacional (processamentos) acirram os conflitos entre posse e propriedade ao fazer das partilhas e das colaborações a melhor resolução de um agente em busca de seu próprio benefício. 
Cabe também apontar que um espaço construído através da virtualidade pode se subdividir infinitamente sem maiores custos, como antes apenas era capacitado ao tempo. O espaço virtual pode, deste modo, se transformar e multiplicar na mesma velocidade dos interesses e afetos, garantindo sua reunião e ordenação sem limitar sua orientação e movimentação. Mesmo a distância cognitiva - que emerge com a reprodução barata e ilimitada da informação disponível — é relativizada pelas facilidades de construção de teias de comunicação e de uso de agentes de localização desenvolvidos nas interfaces. Por outro lado a simplicidade em aderir ou abandonar as comunidades transformam o sentido de identidade e pertencimento, fazendo com que o anonimato e a mobilidade não sejam mais antitéticos à reputação e segurança. A reputabilidade e a resolução de dilemas agora se desenvolvem através de mecanismos de auto-valoração e de auto-regulação embutidos nas próprias interfaces. (Rheingold, 2002) A participação e a ação comum ganham grande maleabilidade, transformando as comunidades virtuais em comunidades de movimento que esboroam as fronteiras entre o público e o privado, pois o interesse individual torna-se o comum e as exigências públicas demarcam o exclusivo.

\section{Agente, ativismo e ação direta: indeterminação}

Por outro lado, é importante assinalar a emergência da noção de hacker como agente indeterminado que intervém em todos os momentos da construção da CMC e da TIC, seja para ampliar seu poder de cooperação, seja para cronificar seu poder de conflito. Por um lado, não é possível caracterizá-lo com os contornos definidos através da sociologia (não pode ser circunscrito a uma ideologia, classe social, geração, gênero ou atividade). Por outro, é difícil enquadrá-lo com precisão através das formas da economia política (ele não está restrito ao universo seja dos profissionais de administração de rede, seja dos profissionais de análise e programação de sistemas).

O hacker emerge como um agente indeterminado capaz de se ocupar de todas as diferentes atividades que compõem o universo da CMC e da TIC. Desenvolvimento de linguagens de programação, configuração e alteração de hardware, produção e transformação de software, desenvolvimento de sistemas operacionais, desenvolvimento de jogos eletrônicos, criação e administração de redes; em todas as áreas o hacker é o mago 
capaz de realizar o que é vedado às demais criaturas (Levy, 1994). Se considerarmos, entretanto, que a rede institucionalmente foi constituída tanto pelos interesses oriundos da segurança territorial e política, para resolver questões militares de conflito mundial, quanto pelos interesses oriundos da educação e pesquisa científica, para resolver problemas de cooperação em pesquisa; o hacker surge como um agente móvel que vem de fora das instituições (Rheingold, 1993). Embora a noção de hacker se transforme ao longo da genealogia das redes, a ele é dado sempre o lugar de promoção e disseminação do povoamento do ciberespaço, construindo as interfaces que facilitam seu uso. Ele é o "nativo" do espaço virtual das redes. Por isso não causa tanta estranheza vê-lo hoje ocupar, ao mesmo tempo, o lugar de atitude modelar para a geração dos princípios determinantes de uma nova moral fundada no trabalho (Himanem, 2001); e o lugar de modelo geral da atitude de delinqüência criminosa terrorista (Vegh, 2005). Acompanhar os diferentes sentidos solidários aos diferentes acontecimentos atribuídos ao hacker permite assinalar o movimento das forças que vem de fora, ocasionando tanto as perturbações e ameaças ao controle, quanto o desenvolvimento de seus dispositivos e mecanismos.

Temos, ainda, o ativismo como atitude crescente, beneficiada pela facilidade de construir redes de parcerias para resolver os problemas de partilha e de disputa. O ativista abandona a mediação das instituições para a realização de suas ações, na mesma medida em que encontra facilidade de construir, com as interfaces, redes de ação direta para reunir possíveis colaboradores capazes de amparar sua ação. Estas redes de parceria são capazes, por um lado, de converter a potência de cooperação da rede em um poder de valoração dos negócios e dos produtos pela comunicação viva e colaborativa.

O mecanismo de avaliação de um produto ou opinião pelos próprios compradores e leitores na interface da Amazon, ou o mecanismo de avaliação dos compradores e vendedores por eles próprios na interface do Ebay formam redes de parceria que agregam um alto valor às empresas através do processo de partilha graciosa (Rheingold, 2002). Por outro lado, a rede de programadores vinculados ao projeto do sistema operacional Linux gera um grande valor às interfaces que eles próprios desenvolvem para o sistema (Raymond, 2000). 
O movimento de ação política Move On usou a lei 80/20 que prevê a formação de eixos (bubs) na rede de distribuição para organizar uma parceria de ativistas, que em apenas um mês promoveu as manifestações mundiais contrárias à guerra do Iraque, levando milhões de pessoas às ruas no mesmo dia. A rede de notícias proposta pelo jornalista Christopher Allbritton, através do blog Back to Iraq 2.0, fez de seus leitores parceiros e colaboradores no financiamento de sua cobertura independente da guerra do Iraque. A rede de arrecadação de fundos, através do blog Dean for América, para a campanha de Howard Dean, um desconhecido governador de Vermont, fez de seus eleitores parceiros no financiamento de sua campanha para indicação de candidatura pelo Partido Democrata dos EUA (Trippi, 2004).

Mas estas parcerias são indissociáveis dos confrontos, eliminações e disputas implicadas nelas. A Amazon e o E-bay eliminam empregos e afirmam a superioridade das chamadas "empresas ponto com" sobre as tradicionais empresas do espaço real (Rheingold, 2002). O movimento Linux desvaloriza os sistemas operacionais comerciais e afirma a superioridade de seu modelo de produção "bazar" contra o modelo de produção "catedral" da Microsoft (Raymond, 2000). O Move On esvazia as instituições representativas de valor e afirma sua superioridade sobre os partidos políticos e sindicatos. O jornalista reduz o valor das notícias das grandes agências e jornais e afirma a independência de seu trabalho diretamente financiado pelos leitores contra o trabalho assalariado gerido pelas empresas. O candidato diretamente promovido e financiado pelos eleitores reduz o valor do trabalho de divulgação e promoção das mídias corporativas e afirma o valor de sua candidatura contra aquelas financiadas pelos bancos e grandes corporações (Trippi, 2004). A mobilidade do ativismo dissolve as necessidades de associação e filiação como mediadores validos para a construção da colaboração, indiferenciando a partilha e a disputa em suas redes de parceria.

\section{Da curva de sino para a lei de potência}

A rede interativa de comunicação distribuída foi criada para ser um sistema com um design voltado para o usuário final (Saltzer, Reed e Clark, 1984). Este tipo de raciocínio projetual é contrário à implementação de funções especializadas nos sistemas e meios de 
comunicação, com vistas a ampliar sua adaptabilidade aos desejos dos usuários. Parte do princípio que um sistema ou um meio estúpido capacita melhor a inteligência dos serviços e dos usuários. O nível básico de um sistema deveria suportar que a mais ampla variedade de serviços e funções possíveis pudessem ser criadas de modo a permitir mesmo aplicações impossíveis de serem antecipadas (Saltzer, Reed e Clark, 1998). A contrapartida é a rede de comunicação de massa com um sistema inteligente de funções implementadas em sua infra-estrutura, gerando os usuários estúpidos com sua cultura de bits, seus produtos arrasa quarteirão e seu homem mediano medido pela curva de Gauss - a popular curva de sino.

A curva de sino e seu correlato homem médio já foi o símbolo máximo das esperanças democráticas. A grande concentração no centro da curva e a relativa insignificância das acumulações nos extremos do mais e do menos significavam que nossos interesses eram bastante homogêneos. Por isso mesmo, podíamos concluir que eles estavam bem representados nas políticas de massa de nossos candidatos políticos ou nos produtos de massa das grandes corporações. O homem médio que consumia os produtos arrasa quarteirão (blockbuster) era considerado o mais sólido esteio da democracia.

Na década de 90, porém, uma interpretação conservadora e autoritária da curva de sino rezava que a inteligência era hereditária e a elite intelectual eterna, o que tornaria inviável qualquer política de educação (Hernstein e Murray, 1994). Porque o foco se deslocara da grande acumulação no centro da curva para as suas extremidades? As revoltas anti-disciplinares iniciadas nos anos 60 no mundo capitalista vão terminar no final dos 80 com a queda do muro de Berlim e o fim das sociedades comunistas. Com o fim da disciplina como diagrama de poder o indivíduo normal, o homem médio, desaparece como tipo padrão. Se antes nos comprazíamos com a oferta do produto médio capaz de gerar o grande sucesso, desprezando os extremos da curva de sino; agora descobríamos que habitávamos vários desses extremos onde, para melhor ou pior, éramos excepcionais em algo e nossos interesses de fato vibravam mais e se concentravam sobretudo nesses extremos.

Mas a passagem da curva de sino para a lei de potência não precisa significar, como querem os mais apressados, o ocaso da democracia e a aurora da tirania totalitária emersa 
do caos anárquico. A regra 80/20 aliada à tendência do rico ficar mais rico, ou mesmo ficar com tudo, não precisa ter uma interpretação tão negativa e antidemocrática. No mercado de massa o alto custo de manutenção do pé quadrado de espaço na prateleira do shopping ou do supermercado fazia com que a variedade dos produtos ficasse limitada aos de alta rotatividade e grande saída. Muitos consumiam poucos produtos. Mas o custo quase nulo aliado aos dispositivos de busca, recomendação e customização fizeram das lojas virtuais um local onde a lei da potência passasse a beneficiar a variedade, desigualdade e a qualidade em detrimento do grande sucesso e do produto arrasa quarteirão (blockbuster).

Da desigualdade da distribuição de riqueza observada pelo economista Vilfredo Pareto, que revelava a concentração de $80 \%$ dela nas mãos de $20 \%$ da população, à desigualdade de freqüência no uso das palavras observada pelo lingüista George Zipf vamos encontrar a ubiqüidade das distribuições de lei de potência com suas curvas na forma $1 / x$ - curvas cuja amplitude jamais chega a zero se estendendo até o infinito. Se pularmos dos 180 mil produtos que uma grande loja pode oferecer para os mais de 800 mil que uma loja virtual oferece ganhamos o poder de explorar essa cauda, amenizando a regra 80/20 para lucro da produção de maior qualidade e menor público.

As distribuições de lei de potência ocorrem quando as coisas são diferentes, algumas são melhores do que as outras, e efeitos como reputação podem promover os itens bons e suprimir os itens maus. Daí resulta o que Pareto denominou "desequilíbrios previsíveis" dos mercados, da cultura e da sociedade: o sucesso chama o sucesso (Anderson, 2006, p. 124-125).

Estamos vivendo a passagem do mundo do homem médio, detectado pela curva de sino e governado pela cultura de massa, para o mundo dos agentes medido pela lei de potência e vivido na vasta quantidade de tribos com seus nichos abrigados na cauda longa do mercado da Internet:

As pessoas estão formando milhares de tribos de interesse culturais, conectadas menos pela proximidade geográfica e pelos bate-papos no local de trabalho do que pelas preferências comuns. Em outras palavras, estamos deixando para trás a era do bebedouro, quando quase todos víamos, ouvíamos e líamos as mesmas coisas, que constituíam um conjunto relativamente pequeno de grandes sucessos. E estamos entrando na era da microcultura, quando todos escolhemos coisas diferentes (Anderson, 2006, p.183). 
Para compreendermos as redes de lei de potência precisamos remover sua casca, irmos além da estrutura e da topologia como incita Barabási, pois a rede é apenas o esqueleto da complexidade, as vias para os diversos processos que fazem nosso mundo soar. Nelas a narrativa é hipertextual, fazendo com que a dinâmica que tem lugar no tráfego entre as ligações (links) seja mais importante do que a estrutura e a topologia, pois só ela revela a viva interação entre os membros da rede. (Barabási, 2002) A remoção da casca implica o mergulho nos interesses e na intensa conversação das comunidades virtuais ou dos grupos de afinidades, atentos a seus desdobramentos na intensa ligação entre os grupos e as células que formam nas redes de manifestações, constituindo a narrativa como um "fala-se" sem fim nem começo onde a comunicação ultrapassa a informação circulante.

A partir desta perspectiva acreditamos que o ciberespaço não se organizaria em massas, mas em multidões (Negri, 2003), distribuídas em comunidades virtuais e integradas em forma de rede (Rheingold, 2002). Ele teria se constituído como um meio da multidão, (Antoun, 2004) o lugar onde a multidão pode estruturar e experimentar suas formas singulares de luta e organização (Dyer-Witheford, 1999), resistindo à sua dissolução nas organizações populares e nas organizações de massa e podendo eliminar a relação de soberania. (Negri, 2003) Nele encontraríamos os pequenos grupos diferenciados que se multiplicam e se diversificam sem cessar (Antoun, 2004). Estes grupos, mesmo quando formam uma grande aglomeração em um movimento de afluência (swarming), (Arquilla e Ronfeldt, 2000) se organizam em seu interior em pequenos bandos ordenados pelas afinidades (Starhawk, 2000) e integrados por uma rede móvel de interação (Armond, 2000).

\section{Referências bibliográficas:}

ANTOUN, H. 2004. Democracia, multidão e guerra no ciberespaço. In: PARENTE, A. (org.), Tramas da Rede, Porto Alegre, Sulina, p.209-237.

ARMOND, P. 2000. Black Flag Over Seattle. Albion Monitor, 72. Disponível em: http://www.albionmonitor.com/seattlewto/index.html.

ANDERSON, C. 2006. A Cauda Longa: Do mercado de massa para o mercado de nicho. Rio de Janeiro, Campus.

2004. The Long Tail. Wired, 12(10): 170-177. Disponível em: http://www.wired.com/wired/archive/12.10/tail.html. 
ARQUILLA, J. e RONFELDT, D. 2001. Networks, Netwars and the Fight for the Future. First Monday, 6(10). Disponível em:

http://www.firstmonday.org/issues/issue6_10/ronfeldt/index.html. (orgs.) 2001. Networks and Netwars: the future of terror, crime and militancy.

Santa Monica, RAND. Disponível em: http://www.rand.org/publications/MR/MR1382.

2000. Swarming and the Future of Conflict. Santa Monica, RAND. Disponivel em: http://www.rand.org/publications/DB/DB311.

1999. The Emergence of Noopolitik: toward an American information strategy.

Santa Monica, RAND. Disponível em: http://www.rand.org/publications/MR/MR1033.

1996. The Advent of Netwar. Santa Monica, RAND. Disponível em:

http://www.rand.org/publications/MR/MR789.

1993. Cyberwar is Coming. Comparative Strategy, 12(2):141-165. Disponível em: http://gopher.well.sf.ca.us:70/0/Military/cyberwar.

ARQUILLA, J., RONFELDT, D., FULLER, G. E. e FULLER, M. F. 1998. The Zapatista "Social Netwar" in Mexico. Santa Monica, RAND. Disponível em http://www.rand.org/publications/MR/MR994.

AXELROD, R. 1985. The Evolution of Cooperation. Nova Iorque, Basic Books.

BARABÁSI, A-L. 2002. Linked: the new science of networks. Cambridge, Perseus.

BEAM, L. 1992. Leaderless Resistance. The Seditionist, 12. Disponível em: http://www.louisbeam.com/leaderless.htm.

CAPRA, F. 1996. The Web of Life. Nova Iorque, Anchor.

CLEAVER, H. 1994. The Chiapas Uprising and the Future of Class Struggle in the New World Order. Common Sense 2(15):5-17. Disponível em: http://www.eco.utexas.edu/facstaff/Cleaver/chiapasuprising.html.

2000. Reading Capital Politically. São Francisco, AK Press.

COLE, J. I. e SUMAN, M. (orgs.) 2003. The UCLA Internet Report: Surveying the digital future. Los Angeles, University of California . Disponível em: http://www.digitalcenter.org/pdf/InternetReportYearThree.pdf.

DELEUZE, G. 1992. Conversações. Rio de Janeiro, 34.

1988. Foucault. São Paulo, Brasiliense.

DELEUZE, G. e GUATTARI, F. 1980. Mille Plateaux. Paris, Minuit.

DYER-WITHEFORD, N. 1999. Cyber-Marx: cycles and circuits of struggle in high-technology capitalism. Chicago, University of Illinois.

FOUCAULT, M. 2002. Em Defesa da Sociedade. São Paulo, Martins Fontes. 1977. História da Sexualidade I: A vontade de saber. Rio de Janeiro, Graal. 1977. Vigiar e Punir: A história da violência nas prisões. Rio de Janeiro, Vozes.

FRAUENFELDER, M. 2002. Outsmarting the Tragedy of the Commons. The Feature. Disponível em: http://www.thefeature.com/article?articleid=15578. 
GERLACH, L. P. 1987. Protest Movement and the Construction of Risk. In: B. B.

JOHNSON e V. T. COVELLO (eds.), The Social and Cultural Construction of Risk: Essays on Risk Selection and Perception, Boston, Reidel, p.103-145.

HENWOOD, D. 2003. After the new economy. Nova Iorque, The New Press.

HERRNSTEIN, R. J. e MURRAY, C. 1994. The Bell Curve: Intelligence and Class Structure in American Life. Nova Iorque, Free Press.

GOFFMAN, E. 1959. The Presentation of Self in Everiday Life. Garden City, Doubleday.

GRAEBER, D. 2002. The New Anarchists. New Left Review, 3(13):61-73. Disponível em: http://www.newleftreview.net/NLR24704.shtml.

HARDIN, G. 1968. The Tragedy of the Commons. Science, 162:1243-1248. Disponível em: http://dieoff.com/page95.htm.

HIMANEN, P. 2001. The hacker ethic and the spirit of the information age. Nova Iorque, Random House.

HOBBES, T. 1997. Leviathan. Nova Iorque, W. W. Norton.

HUXLEY, T. H. 2003. The Struggle for Existence in Human Society. In: Evolution and Ethics and Other Essays, McLean, Indypublish.Com.

JOHNSON, S. 2001. Emergence: The Connected Lives of Ants, Brains, Cities, and Software.

Nova Iorque, Scribner.

KATZ, J. E. e ASPDEN, P. 1997. Cyberspace and Social Community Development: Internet use and its community integration correlates. Nova Iorque, Center for Research on Information Society. Disponível em: http://www.nicoladoering.de/Hogrefe/katz2.htm.

KELLY, K. 1994. Out of Control: the rise of neo-biological civilization. Nova Iorque, Addison-Wesley.

KIRSNER, S. 1998. The Legend of Bob Metcalfe. Wired, 6(11). Disponível em: http://www.wired.com/wired/archive/6.11/metcalfe.html.

KOLLOCK, P. 1998. Social Dilemmas: The Anatomy of Cooperation. Annual Review of

Sociology, 24:183-214. Disponível em:

http://www.sscnet.ucla.edu/soc/faculty/kollock/classes/cooperation/resources/Kollock 1998 Social Dilemmas.pdf.

KOLLOCK, P. e SMITH, M. 1996. Managing the Virtual Commons: cooperation and conflict in computer communities. In: S. HERRING, (ed.), Computer-Mediated Communication, Amsterdam, John Benjamins, p. 109-128. Disponível em: http:// netscan.sscnet.ucla.edu/csoc/papers/virtcomm/vcommons.htm.

KOPP, C. 2000. Information Warfare: A Fundamental Paradigm of Infowar. Systems: Enterprise Computing Monthly, Fevereiro:46-55.

KRAUT, R., LUNDMARK, V., PAT'TERSON, M., KIESLER, S., MUKOPADHYAY, T. e SCHERLIS, W. 1998. Internet Paradox: a social technology that reduces social involvement and psychological well-being? American Psychologist, 53(9):1017-1031. Disponível em: http://www.apa.org/journals/amp/amp5391017.html.

KROPOTKIN, P. 1989. Mutual Aid: a factor of evolution. Montreal, Black Rose. 
LAZZARATO, M. e NEGRI, A. 2001. Trabalho Imaterial: formas de vida e produção de subjetividade. Rio de Janeiro, DP\&A.

LESSIG, L. 2001. The Future of Ideas: the fate of the commons in a connected world. Nova Iorque, Random House.

1999. Code and other laws of cyberspace. Nova Iorque, Perseus.

LEVY, S. 1994. Hackers - heroes of the computer revolution. Londres, Penguin.

LOCKE, J. 1952. Two Treatises of Government. Nova Iorque, Prentice-Hall.

MARX, K. 1993. Grundrisse: Foundations of the Critique of Political Economy (Rough Draft). London, Penguin.

1988. O Processo de Produção do Capital. In: K. MARX, O Capital: crítica da economia politica. São Paulo, Nova Cultural, p. 142-164.

MINAR, N. e HEDLUND, M. 2001. A Network of Peers: peer-to-peer model through the history of the Internet. In: A. ORAM (ed.), Peer-to-Peer: harnessing the power of disruptive technologies. Sebastopol, O'Reilly, p. 3-20. Disponível em:

http://www.oreilly.com/catalog/peertopeer/chapter/ch01.html.

NEGRI, A. 2003. Cinco lições sobre Império. Rio de Janeiro, DP\&A.

2002. O Poder constituinte — ensaio sobre as alternativas da modernidade.

Rio de Janeiro, DP\&A.

1989. Marx Beyond Marx: lessons on the Gründrisse. São Francisco, Autonomedia.

NEGRI, A. e HARDT, M. 2004. Multitude: war and democracy in the Age of Empire. Nova Iorque, Penguin.

2001. Império. Rio de Janeiro, Record.

RAYMOND, E. S. 1998. The Cathedral \& the Bazaar. First Monday, 3(3). Disponível em: http://www.firstmonday.org/issues/issue3_3/index.html.

RAYMOND, E. S. et al. 2000. The Cathedral \& The Bazaar. Sebastopol, O'Reilly.

REED, D. P. 1999. Digital Strategy: Weapons of Math Destruction. Context Magazine, 2(1).

Disponível em http:/ / www.contextmag.com/archives/199903/DigitalStrategy.asp.

1999a. That Sneaky Exponential - Beyond Metcalfe's Law to the Power of Community Building. Context Magazine, 2(1). Disponível em http://www.contextmag.com/archives/199903/DigitalStrategyReedsLaw.asp.

RHEINGOLD, H. 2002. Smart Mobs: the next social revolution. Cambridge, Perseus.

1993. The Virtual Community: homesteading on the electronic frontier. Nova Iorque, Harper Collins.

SALTZER, J. H., REED, D. P. e CLARK, D. D. 1984. End-to-end arguments in system design. ACM Transactions on Computer Systems, 2(4):277-288. Disponível em: http://www.reed.com/Papers/EndtoEnd.html.

1998. Comment on Active Networking and End-to-end Arguments. IEEE Communications Magazine, 12(3):69-71. Disponível em: http://web.mit.edu/Saltzer/www/publications/endtoend/ANe2ecomment.html. 
SCHWARTAU, W. 1995. Information W arfare. Nova Iorque, Thunder's Mouth.

SMITH, M. A. 2000. Some Social Implications of Ubiquitous Wireless Networks. Mobile Computing and Communications Review, 4(2):25-36. Disponível em: http://www.research.microsoft.com/ masmith/Social Implications of Ubiquitous Wireless Networks - Final.doc.

STARHAWK 2000. Como bloqueamos a OMC. Lugar Comum - Estudos de Midia, Cultura e Democracia, 4(11):9-14.

TRIPPI, J. 2004. The Revolution Will Not Be Televised: democracy, the internet, and the overtbrow of everything. Nova Iorque, Harper Collins.

VAIDHYANATHAN, S. 2004. The Anarchist in the Library: How the clash between freedom and control is hacking the real world and crashing the system. Nova Iorque, Perseus.

2003. The new information ecosystem: cultures of anarchy and closure. In: P2P: the new information war? London, Open Democracy. Disponível em: http://opendemocracy.net/debates/article-8-101-1319.jsp.

VEGH, S. 2005. The media portrayal of hacking, hackers, and hacktivism before and after September 11. First Monday, 10(2). Disponível em: http://www.firstmonday.org/issues/issue10_2/vegh/index.html.

WEINBERGER, D. 2003. Small Pieces Loosely Joined: A unified theory of web. Cambridge, Perseus.

WHINE, M. 1999. Cyberspace: a new medium for communication, command and control by extremists. In: Studies in Conflict and Terrorism, Santa Monica, RAND. Disponível em: http://www.ict.org.il/articles/articledet.cfm?articleid $=76$.

WRAY, S. 1998. Electronic Civil Disobedience and the World Wide Web of Hacktivism. Nova Iorque, Drake University. Disponível em: http://www.d-i-na.net/txt/cache/wwwhack.htm.

WRIGHT, S. 2002. Storming Heaven: Class composition and struggle in Italian Autonomist Marxism. Londres, Pluto. 